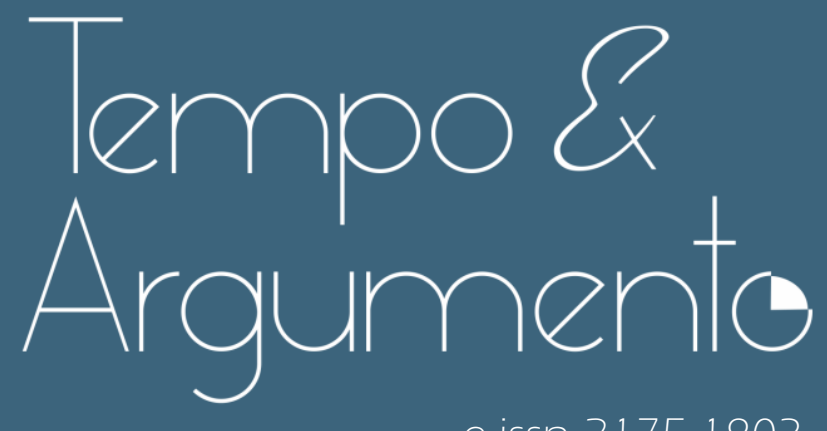

e-issn 2175-1803

\title{
Impressos, discursos e moralidade nos regimes autoritários instituidos no Brasil
}

Resenha da obra:

COWAN, Benjamin A. Securing sex: morality and repression in the making of Cold War Brazil. Chapel Hill, NC: University of North Carolina Press, 2016.

- Jorge Luiz Zaluski

Doutorando no Programa de Pós-Graduação em História da

Universidade do Estado de Santa Catarina (UDESC).

Florianópolis, SC - BRASIL

lattes.cnpq.br/6749402096791048

jorgezaluski@hotmail.com

(D) orcid.org/0000-0003-0795-263X

Para citar esta resenha:

COWAN, Benjamin A. Securing sex: morality and repression in the making of Cold War Brazil. Chapel Hill, NC: University of North Carolina Press, 2016 . Resenha de: ZALUSKI, Jorge Luiz. Impressos, discursos e moralidade nos regimes autoritários instituídos no Brasil. Revista Tempo e Argumento, Florianópolis, v. 12, n. 29, e050 1. jan/abr. 2020.

doi http://dx.doi.org/10.5965/2175180312292020e0501

Recebido: 04/07/2019

Aprovado: $31 / 03 / 2020$ 


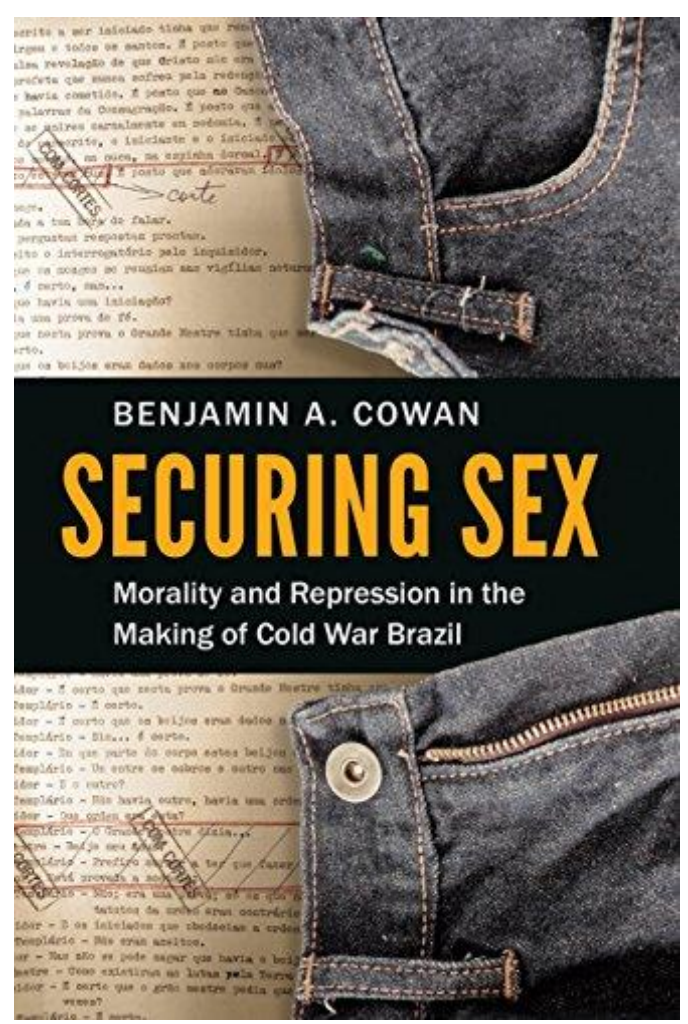

Resenha da obra:

COWAN, Benjamin A. Securing sex: morality and repression in the making of Cold War Brazil. Chapel Hill, NC: University of North Carolina Press, 2016.

Atualmente, os regimes autoritários instituídos durante o século XX na América do Sul e na América Central constituem tema de muitas investigações científicas e, ainda, um profícuo campo de pesquisa na historiografia. No livro Securing sex: morality and repression in the making of cold War Brazil, Benjamin A. Cowan apresenta uma interpretação sobre determinadas "facetas" dos regimes autoritários instituídos no Brasil, centrando o foco de sua análise na ditadura militar que governou o país entre 1964 e 1985. O autor é Doutor em História pela Universidade da Califórnia em Los Angeles (UCLA) e realizou estudos sobre as temáticas relações de gênero, sexualidade, movimentos sociais da denominada direita e violências no século XX. Essa obra, que recebeu o prêmio da Associação de Estudos Latino-Americanos (Latino American Studies Association [LASA]) em 2017, ainda não tem tradução para o português.

Para a elaboração da narrativa histórica, o historiador analisou 35 impressos publicados no Brasil entre as décadas de 1930 e 1980. Dentre esses impressos se encontram os jornais O Estado de S. Paulo, Correio da Manhã e O Globo, que circulavam em diversos estados da federação. As revistas de informação, como Claudia, Veja, Manchete, e as revistas produzidas por instituições militares, com ênfase para A Defesa Nacional, Revista Militar Brasileira e Segurança e Desenvolvimento também fazem parte da documentação investigada. Tais impressos foram pesquisados pelo autor em várias instituições, com destaque para o Arquivo Nacional, o Arquivo Nacional do 
Exército, a Biblioteca da Academia Militar das Agulhas Negras e a Biblioteca do Exército.

A obra se divide em 7 capítulos, que têm como "fio condutor" as ações de diferentes naturezas adotadas por representantes do Estado brasileiro e pelos civis para combater o que foi considerado um "desvio moral" da população à época. O autor, no processo de construção da narrativa histórica, apoia-se no referencial conceitual relativo ao "pânico moral", idealizado pelo sociólogo sulafricano Stanley Cohen na década de 1970. Benjamin A. Cowan afirma que as mudanças socioculturais ocorridas na sociedade brasileira na segunda metade do século XX geraram novas experiências que provocaram grande preocupação em grupos sociais identificados no campo da política como de direita.

O autor destaca que algumas premissas dos discursos autoritários e moralistas estão presentes na sociedade brasileira durante grande parte do século XX. No primeiro capítulo da obra, intitulado "Only for the cause of the pátria: the frustrations of interwar moralism" (tradução livre: Somente pela causa da pátria: as frustrações do moralismo no entreguerras), Cowan analisa como a política socioeconômica adotada no primeiro governo de Getúlio Vargas (19301945) contribuiu para instaurar em uma significativa parcela da população novas práticas e novos valores, que acabaram sendo alvo de questionamento por parte de intelectuais, religiosos, juristas e outros personagens identificados com a direita. Para Cowan, parte dos grupos sociais de direita, entre eles integrantes do Movimento Integralista e católicos, que associaram as novas práticas e os novos valores a 2 processos: a) ao comunismo; e b) a uma crise moral que colocava em xeque muitos dos "valores tradicionais da família brasileira" (aqui entendida como a configuração de família das elites), inclusive os relativos à masculinidade. Segundo o autor, o governo de Getúlio Vargas, especialmente durante a Ditadura do Estado Novo, como "resposta" ao referido quadro, optou por manter um estreito "diálogo" com os grupos sociais de direita, adotando políticas nos campos da educação escolar, da assistência social etc. que instituíam e/ou reforçavam uma configuração de família nuclear associada aos valores burgueses e com distinções de gênero. 
Na década de 1960 e no início da década de 1970, a política socioeconômica implementada durante o "Milagre Econômico" pelos governantes da ditatura provocou novas mudanças no âmbito da família e das relações de gênero que foram alvo de questionamentos de grupos sociais de direita. No segundo capítulo da obra, intitulado "Sexual revolution? Contexts of countersubversive moralism" (tradução livre: Revolução sexual? Contextos do moralismo contrassubversivo), Cowan explora como se deu a aproximação entre os civis e os governantes militares, com o objetivo de combater os considerados subversivos. Por meio da análise das revistas Manchete e Realidade, o pesquisador observou que temas como juventude, sexualidade e moralismo estiveram no centro de debates públicos na década de 1960, muitas vezes associados aos discursos comunistas. O autor destaca que muitos jovens brasileiros das diferentes camadas sociais não estavam interessados nos debates públicos da época sobre família e sexualidade. Apesar desse fato, a produção de discursos para a "proteção" da família nuclear burguesa e de determinada perspectiva de sexualidade heteronormativa foi bastante grande. Esses discursos de cunho moralista incitaram a ampliação da vigilância sobre as escolas ginasiais e secundárias e as universidades, vistas como espaços privilegiados onde se propagavam ideais considerados subversivos.

No terceiro capítulo, intitulado "Sexual revolution! Moral panic and the repressive right" (tradução livre: Revolução sexual! Pânico moral e direita repressiva), Cowan enfoca as relações estabelecidas em nível transnacional entre grupos de direita do Brasil e do exterior. Para o autor, após as manifestações estudantis de maio de 1968 emergiu um discurso de crise cultural no Ocidente que contribuiu para a construção de muitas narrativas voltadas ao combate do comunismo e à defesa da família nuclear burguesa. No Brasil, tal discurso foi difundido por meio da ideia de "pânico moral", que apresentava a resistência armada, a delinquência juvenil e a crítica às relações de gênero como sinônimos de uma crise moral que supostamente destruiria a juventude brasileira. Segundo o autor, integrantes de movimentos sociais, como Tradição, Família e Propriedade (TFP) e Rearmamento Moral do Brasil (RM), tinham por "missão" defender as práticas e os valores morais da família brasileira. Por meio da revista Doutrina de 
Segurança Nacional, o autor analisou os discursos de membros dos referidos movimentos sociais que foram utilizados para sustentar o moralismo instituído no período e proporcionar legitimidade às ações do Estado brasileiro de diferentes ordens contra aqueles que rompiam com práticas e valores relativos à família compartilhados pela direita.

No quarto capítulo, intitulado "Drugs, anarchism, and eroticism: moral technocracy and the military regime" (tradução livre: Drogas, anarquismo e erotismo: tecnocracia moral e o regime militar), Cowan aborda o papel desempenhado pelos tecnocratas durante a ditadura militar em relação às temáticas familia e relações de gênero. Juristas, filósofos, educadores, médicos etc. publicavam artigos na Revista da Escola Superior de Guerra, considerada um dos principais "porta-vozes" do regime autoritário. Esses técnicos, que atuam em diferentes setores da burocracia, sobretudo da federal, partilhavam do ideário que atribuía aos comunistas a difusão de ideais sobre a "liberação das mulheres" que ocasionavam a "degeneração da família" e o "problema da juventude". A juventude, nesse discurso, era considerada delinquente, usuária de drogas e portadora de práticas e valores relativos à sexualidade que necessitavam ser controlados. Para o autor, o discurso enunciado por esses burocratas se mostrou de fundamental importância na construção de leis e na implementação de políticas sociais no período. Dentre essas leis se destacam o Código de Menores, de 1979, e a Lei do Divórcio, aprovada em 1977 1.

No quinto capítulo, intitulado "Young ladies seduced and carried off by terrorists: secrets, spies, and anticommunist moral panic" (tradução livre: Moças seduzidas e levadas por terroristas: segredos, espiões e pânico moral anticomunista), o autor investiga os discursos que acusavam uma parcela das mulheres brasileiras de ser responsáveis pela divulgação de discursos de cunho subversivo. As revistas Ação Democrática e A Defesa Nacional dedicaram inúmeras páginas a esse ideário antifeminista e anticomunista. Segundo o historiador, essas duas concepções conjugadas favoreceram a perseguição e a tortura de muitas jovens que integraram os agrupamentos políticos contrários ao regime ditatorial.

\footnotetext{
${ }^{1}$ Lei n. 6.667, de 10 de outubro de 1979, que estabelece o código de Menores de 1979 e Lei n. 6.515, de 26 de dezembro de 1977, que institui oficialmente o divórcio.
} 
Em "Brazil counts on its sons for redemption moral, civic, and countersubversive education" (tradução livre: O Brasil conta com seus filhos para a redenção moral, cívica e a educação contrassubversiva), sexto capítulo do livro, Cowan analisa como a disciplina escolar Educação Moral e Cívica (EMC) foi utilizada como "instrumento" de combate ao comunismo. Para o historiador, a EMC articulou em seu conteúdo programático as preocupações construídas em torno do "pânico moral" anticomunista. Por meio da disciplina, esse discurso circulou em larga escala em materiais didáticos produzidos para o ensino ginasial da época. Na revista $A$ Defesa Nacional, por exemplo, eram recorrentes os artigos que entendiam que a escola deveria difundir entre os alunos noções sobre uma masculinidade que subsidiasse a preparação para a carreira militar, bem como para a edificação de uma família nuclear.

No último capítulo do livro, intitulado "From pornography to the pill: bagunça and the limitations of moralist efficacy" (tradução livre: Da pornografia à pílula: bagunça e as limitações da eficácia moralista), Cowan analisa as "fissuras" presentes nos discursos sobre o uso de métodos contraceptivos pelas mulheres durante o processo de redemocratização, iniciado no final da década de 1970. Temas como controle da natalidade e pornografia ganharam destaque nos debates sobre saúde pública do país. Para o autor, os defensores do regime ditatorial teceram largas críticas às políticas sociais colocadas em prática na época, que distribuíam contraceptivos para a população e também passaram a associar o processo de redemocratização à ideia de retrocesso político.

É notável como o historiador mobilizou um grande número de fontes na obra Securing sex: morality and repression in the making of Cold War Brazil, que possibilitou a produção de reflexões inovadoras sobre as temáticas estudadas, muitas vezes de modo tangencial, em relação aos regimes autoritários instituídos no Brasil. Soma-se a esse trabalho de pesquisa das fontes o uso de um extenso e atual referencial bibliográfico sobre as ditaduras brasileiras (governo de Getúlio Vargas e ditadura militar) para além das publicadas em português. Esse fato, que permite que o(a) leitor(a) estabeleça conexões entre as produções nacionais e internacionais. Por fim, a obra contribui com os estudos da História do Tempo Presente seja em relação às temáticas estudadas, seja em relação à 
temporalidade dos discursos. Dados os recentes acontecimentos no Brasil, uma parte desse passado parece inseparável, como lembra Henry Rousso (2016, p. 302), "um passado que volta para assombrar o presente".

Referência

ROUSSO, Henry. A última catástrofe: a história, o presente, o contemporâneo. Rio de Janeiro: Ed. FGV, 2016. 